\title{
Noninvasive ventilation and recruitment maneuvers after cardiac surgery: Are we doing enough?
}

\author{
Juan N. Pulido, MD
}

From Cardiothoracic Anesthesiology and Critical Care Medicine, Swedish Heart and Vascular Institute, US Anesthesia Partners Washington, Seattle, Wash.

Disclosures: Author has nothing to disclose with regard to commercial support.

Received for publication May 30, 2018; revisions received May 30, 2018; accepted for publication June 1, 2018; available ahead of print July 17, 2018.

Address for reprints: Juan N. Pulido, MD, Cardiothoracic Anesthesiology and Critical Care Medicine, Swedish Heart and Vascular Institute, US Anesthesia Partners Washington, 550 17th Ave \#680, Seattle, WA 98122 (E-mail: juan.pulido@swedish.org).

J Thorac Cardiovasc Surg 2018;156:2178-9

$0022-5223 / \$ 36.00$

Copyright (c) 2018 by The American Association for Thoracic Surgery

https://doi.org/10.1016/j.jtcvs.2018.06.013

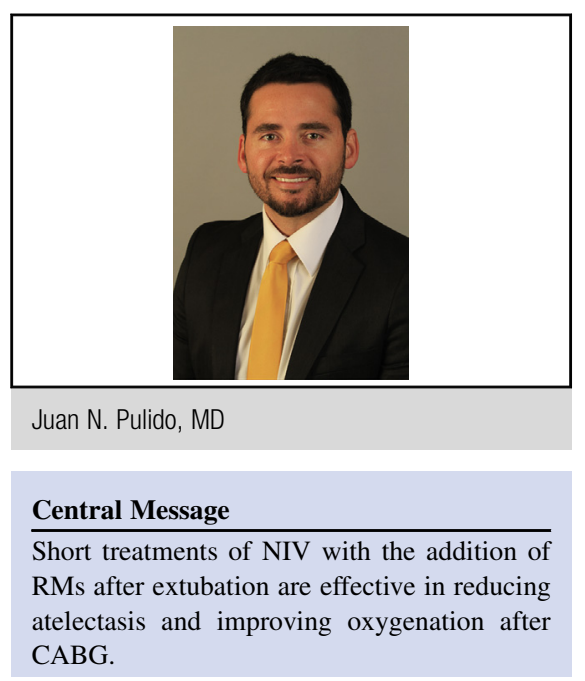

See Article page 2170.
Early extubation has become an important quality initiative after cardiac surgery. A fast-track pathway and enhanced recovery after cardiac surgery ${ }^{1}$ are 2 recognized initiatives and system improvements to accomplish these goals, in addition to other important aspects of care, including weaning of vasoactive medications, early mobilization, multimodal analgesia, and bowel care, all aiming to reduce length of stay and improve value.

Respiratory complications are among the most common complications after cardiac surgery, and the development of atelectasis is by far the most common respiratory consequence of cardiac surgery with cardiopulmonary bypass (CPB). ${ }^{2}$ The combination of general anesthesia with the discontinuation of ventilation at zero positive endexpiratory pressure (PEEP) and cessation of lung circulation during $\mathrm{CPB}$ are the major etiologic factors for the development of atelectasis. Moreover, the addition of an inflammatory response to CPB, ischemia-reperfusion injury, sternotomy, and phrenic nerve manipulation may add reasons for postoperative respiratory failure. Fortunately, in the majority of patients who undergo uncomplicated cardiac surgery, the development of atelectasis is transient and does not impede recovery. Nevertheless, this has been challenged, with some studies demonstrating that the proactive use of noninvasive ventilation (NIV) for the first 24 hours after extubation potentially translates to decreased recovery time ${ }^{3}$ and improvement of lung mechanics and hypoxemia when combined with recruitment maneuvers (RMs). ${ }^{2}$ In the current issue of the Journal, Miura and colleagues ${ }^{4}$ examined the effects of RM during NIV after CABG in a small, single-institution randomized controlled trial. Although this study is small, it is unique because it incorporates a feasible protocol of 30-minute bursts of NIV 3 times per day associated with RM while in the intensive care unit (ICU). The authors included patients with evidence of atelectasis and partial pressure arterial oxygen/ fraction of inspired oxygen less than 300. The grading of atelectasis was objective by using a radiologic atelectasis score (RAS). Patients with a RAS of 2 or greater were included. The control group used NIV with pressure support to maintain tidal volumes of 6 to $8 \mathrm{~mL} / \mathrm{kg}$ and PEEP of $8 \mathrm{~cm} \mathrm{H} 2 \mathrm{O}$, whereas the RM group received PEEP of $15 \mathrm{~cm} \mathrm{H} 2 \mathrm{O}$ for 2 minutes, PEEP $20 \mathrm{~cm} \mathrm{H} 2 \mathrm{O}$ for 2 minutes, and return to PEEP $8 \mathrm{~cm} \mathrm{H} 2 \mathrm{O}$ for the remainder. All patients tolerated the RM, and there were no adverse events, intubation, or death in either group. Arterial blood gases were collected after extubation in room air for 2 minutes (baseline) and daily until discharge from the ICU. Not surprisingly, the RM group demonstrated significant improvement of oxygenation from baseline to discharge and was compared with the control group. Moreover, $94.4 \%$ of patients in the RM group had complete resolution of atelectasis (RAS $=0$ ) compared with $12.5 \%$ in the control group. All patients tolerated the respective treatments, and there was no difference in ICU or hospital length of stay. This study clearly demonstrated that short periods of NIV with an RM protocol are effective in reducing (near eliminating) atelectasis, improving oxygenation, and reducing oxygen requirement after $\mathrm{CABG}$. Although this protocol was well tolerated, the study was powered only to demonstrate improvement in oxygenation; therefore, the safety results or potential larger-scale benefits, such as reduction in length of stay, have to be interpreted with caution because 
further studies would be needed to determine the real benefit or hazard of this approach and the correct patient population, because it was studied only in patients undergoing CABG.

\section{References}

1. Li M, Zhang J, Gan T, Qin G, Wang L, Zhu W, et al. Enhanced recovery after surgery pathway for patients undergoing cardiac surgery: a randomized clinical trial. Eur J Cardiothorac Surg. March 5, 2018 [Epub ahead of print].
2. Celebi S, Köner Ö, Menda F, Omay O, Günay I, Suzer K, et al. Pulmonary effects of noninvasive ventilation combined with the recruitment maneuver after cardiac surgery. Anesth Analg. 2008;107:614-9.

3. Al Jaaly E, Fiorentino F, Reeves BC, Ind PW, Angelini GD, Kemp S, et al. Effect of adding postoperative noninvasive ventilation to usual care to prevent pulmonary complications in patients undergoing coronary artery bypass grafting: a randomized controlled trial. J Thorac Cardiovasc Surg. 2013;146:912-8.

4. Miura MC, Ribeiro de Carvalho CR, Yamada da Silveira LT, Regenga MM, Damiani LP, Fu C. The effects of recruitment maneuver during noninvasive ventilation after coronary bypass grafting: a randomized trial. J Thorac Cardiovasc Surg. 2018;156:2170-7.e1. 